\title{
Identifying breast cancer patients who require a double-check of preoperative core needle biopsy and postoperative surgical specimens to determine the molecular subtype of their tumor
}

\author{
Je Hyung Park', Hyun Yul Kim¹, Youn Joo Jung', Dong II Kim¹, Jee Yeon Kim², Hyun-June Paik \\ ${ }^{1}$ Department of Surgery, Pusan National University Yangsan Hospital, Yangsan, Korea \\ ${ }^{2}$ Department of Pathology, Pusan National University Yangsan Hospital, Yangsan, Korea
}

\begin{abstract}
Purpose: Core needle biopsy (CNB) is a widely used procedure for breast cancer diagnosis and analyzing results of immunohistochemistry (IHC). Several studies have shown concordance or discordance in IHC results between CNB and surgical specimens (SS). A double-check (CNB and SS) is inefficient and costly to perform a double-check on all patients. Therefore, it is important to determine which patients would benefit from a double-check.

Methods: We collected the medical records of patients who underwent breast cancer surgery at Pusan National University Yangsan Hospital between April 2009 and June $2018(n=620)$. Molecular subtypes were classified as follows by hormone receptors (HR) and human epidermal growth factor receptor-2 (HER2): HR+/HER2+, HR+/HER2-, HR-/HER2+, HR-/HER2-. Clinicopathological factors including age, obesity, histological grade, preoperative CEA, CA15-3, T stage, N stage, and menopausal status were assessed to determine whether they were associated with subtype change.

Results: Increasing histological grade ( $P<0.001$; odds ratio [OR], 3.693; 95\% confidence interval [CI], 1.941-7.025), preoperative $C E A \geq 5 \mathrm{ng} / \mathrm{mL}(\mathrm{P}=0.042 ; \mathrm{OR}, 2.399 ; 95 \% \mathrm{Cl}, 1.009-5.707)$ and higher $\mathrm{T}$ stage $(\mathrm{P}=0.015 ; 0 \mathrm{R}, 2.241 ; 95 \% \mathrm{Cl}$, 1.152-4.357) were significantly associated with subtype change. On multivariable analyses, subtype changes were more common in high-grade breast cancer $(P<0.001 ; 0 R, 1.077 ; 95 \% \mathrm{Cl}, 1.031-1.113)$ and $\mathrm{CEA} \geq 5(\mathrm{P}=0.032 ; \mathrm{OR}, 2.658 ; 95 \%$ $\mathrm{Cl}, 1.088-6.490)$.

Conclusion: Patients with moderate- to high-grade tumors or CEA $\geq 5 \mathrm{ng} / \mathrm{mL}$ are required a double-check to determine the molecular subtype of breast cancer.

[Ann Surg Treat Res 2019;97(5):223-229]
\end{abstract}

Key Words: Adjuvant, Biopsy, Breast neoplasms, Chemotherapy, Immunohistochemistry, Large-core needle

\section{INTRODUCTION}

Because breast cancer is the most frequently diagnosed cancer and the second most frequent cause of cancer-related death in women, preoperative assessments of diagnostic and prognostic factors are becoming more important in management. Core needle biopsy (CNB) is routinely used for preoperative assessment of patients with breast cancer [1-4].

Breast cancers are heterogeneous tumors that arise from epithelial cells around the mammary ducts. The heterogeneity of mammary tumors has been well documented based on histopathology and clinical outcomes, and these differences
Received June 21, 2019, Revised September 25, 2019,

Accepted October 8, 2019

Corresponding Author: Hyun-June Paik

Department of Surgery, Pusan National University Yangsan Hospitial, 20

Geumo-ro, Mulgeum-eup, Yangsan 50612, Korea

Tel: +82-55-360-2124, Fax: +82-55-360-2154

E-mail: hjpaik80@naver.com

ORCID: https://orcid.org/0000-0002-2749-4165
Copyright (c) 2019, the Korean Surgical Society

(c) Annals of Surgical Treatment and Research is an Open Access Journal. All articles are distributed under the terms of the Creative Commons Attribution NonCommercial License (http://creativecommons.org/licenses/by-nc/4.0/) which permits unrestricted non-commercial use, distribution, and reproduction in any medium, provided the original work is properly cited. 
have become the basis of disease classification. Today, this pathology-based classification has been refined and replaced with molecular classifications that have the potential to combine disease classification and clinical outcome measures [5]. Breast cancer treatment is varied depending on the molecular classification of the tumor [6].

Adjuvant systemic therapy can significantly reduce the rates of breast cancer recurrence and mortality [7,8]. Endocrine therapy is recommended for most patients with hormone receptors (HR) positive tumors because of its efficacy and safety [8]. For human epidermal growth factor receptor-2 (HER2) positive disease, trastuzumab is considered the standard treatment [9]. In addition, chemotherapy is considered an effective option for HR negative tumors or HER2 positive disease [7].

In general, patients with breast cancer undergo a doublecheck of their histopathologic results by comparison of a preoperative CNB and a postoperative surgical specimen (SS). $\mathrm{CNB}$ is a procedure widely used for diagnosis of breast cancer and to provide tissue for immunohistochemistry (IHC) [10-12]. The CNB test has the advantage of providing definitive results for hormone receptor and HER2 expression to inform treatment with neoadjuvant drugs before surgery. $\mathrm{CNB}$ also provides the only suitable material for preoperative molecular testing [1]. Another advantage of CNB is that the tissues obtained give better fixation results compared with SS. Fixation protocols are also more standardized for $\mathrm{CNB}$, while many different protocols exist for the fixation of SS [10]. The 2015 European Society of Medical Oncology Breast Cancer Clinical Practice Guideline recommends a preoperative pathological examination of $\mathrm{CNB}$ that includes determination of the status of the estrogen receptor (ER), progesterone receptor (PR), and HER2 by IHC or fluorescence in situ hybridization $[10,13]$.

Previous studies have highlighted controversies about concordance or discordance between the results for preoperative CNB and postoperative SS [1-3,10,14-17], and about whether a double-check is necessary when the results of both tests are concordant. Such a double-check is inefficient, and because a large number of women are diagnosed with breast cancer every year, it is costly to perform a double-check on all patients [17]. Therefore, it is important to determine which patients would benefit from a double-check.

In this study, breast cancer patients were divided into groups based on whether the CNB and SS results for tumor subtype were concordant or discordant, and the clinicopathological characteristics of each group were compared to determine which clinicopathological characteristics were associated with a change in breast cancer subtype between CNB and SS.

\section{METHODS}

\section{Data collection}

We collected information from the medical records of patients who underwent breast cancer surgery at Pusan National University Yangsan Hospital between April 2009 and June 2018 $(\mathrm{n}=1,353)$. Clinical information obtained included age, body mass index (BMI), menopausal status, tumor-node-metastasis stage, history of neoadjuvant chemotherapy (NAC), the size, number, histological type, and histological grade of tumors, levels of CEA and CA15-3, and tumor expression of ER, PR, and HER2 from both CNB and SS samples. Patients with missing data or with previous NAC were excluded. Also, we excluded patients diagnosed with other histological types such as ductal carcinoma in situ, lobular carcinoma in situ, mucinous, metaplastic, papillary, etc. A total of 620 patients met our inclusion criteria.

\section{Tissue processing and immunohistochemical}

staining for ER, PR, and HER2

Preoperative CNB specimen was fixed by $10 \%$ formalin for 2 hours. Postoperative SS was serially sectioned into thin slices and fixed by $10 \%$ formalin for at least 5 hours. CNB was submitted entirely and SS was submitted at least 2 representative sections of tumor for tissue processing (HistoCore PELORIS 3 Premium Tissue Processing System, Leica Biosystems, IL, USA).

Serial 4- $\mu$ m-thick paraffin-embedded sections from CNB and SS were stained for ER (SP1, Ventana Medical System, Tucson, AZ, USA), PR (1E2, Ventana Medical System, Tucson, AZ, USA) and HER2/neu (4B5, Ventana Medical Systems) by using an automated immune stainer (BenchMark XT; Ventana Medical System). Silver in situ hybridization was performed using HER2/CEP17 dual-probe (Ventana Medical Systems) through an automated stainer (BenchMark XT; Ventana Medical System).

\section{Cutoff values for Hormone receptors (HR; ER or PR), and HER2}

The expression status of tumors for ER, PR, and HER2 was analyzed by IHC using commercially available antibodies against these proteins (Roche/Ventana Corp., Tucson, AZ, USA). IHC staining with anti-ER and anti-PR antibodies was carried out using suitable positive and negative controls. A positive result was defined as staining of $\geq 1 \%$ of tumor cells. A negative result was defined as staining of $<1 \%$ of tumor cells [18].

The results of HER2/neu IHC were scored semi-quantitatively on a scale of $0,1+, 2+$, and $3+$. Scores of 0 and $1+$ are considered negative, $2+$ is considered indeterminate, and $3+$ is considered strongly positive; the likelihood of response to anti-HER2 treatment increases with increasing score. A positive test for HER2 was defined as either an IHC score of $3+$ or an 
IHC score of $2+$ combined with demonstration by silver in situ hybridization of amplification of the gene encoding HER2. The test was performed according to the recommendations of the American Society of Clinical Oncology/College of American Pathologists for HER2 testing in breast cancers [19].

\section{Classification of subtypes}

Breast cancer molecular subtypes were classified based on the results of IHC as follows: HR+/HER2+, HR+/HER2-, HR-/ HER2+, HR-/HER2- [4,20-22].

\section{Classification of obesity}

Height and weight are the simplest and most commonly used measures of obesity. We used BMI defined as weight in kilograms divided by height in meters squared $\left(\mathrm{kg} / \mathrm{m}^{2}\right)$.

We categorized BMI based on World Health Organization Western Pacific Region criteria, which define underweight as BMI $<18.5 \mathrm{~kg} / \mathrm{m}^{2}$, normal weight as $18.5-22.9 \mathrm{~kg} / \mathrm{m}^{2}$, overweight as $\geq 23.0-24.9 \mathrm{~kg} / \mathrm{m}^{2}$, and obesity as $\geq 25.0 \mathrm{~kg} / \mathrm{m}^{2}[23]$.

\section{Cutoff values for CEA and CA15-3}

Various cutoff values for CEA and CA15-3 have been used in breast cancer screening, including for CEA 2.5, 4, 5, and $6 \mathrm{ng} /$ $\mathrm{ml}$ and for CA15-3 30 or $50 \mathrm{U} / \mathrm{mL}$ [24-28]. We selected the most commonly used cutoff values of $\geq 5 \mathrm{ng} / \mathrm{mL}$ for CEA and $\geq 30$ $\mathrm{U} / \mathrm{mL}$ for CA15-3. These values have been used in more than 30 studies and have been shown to have a specificity $>80 \%$ and a sensitivity $>70 \%[29,30]$.

\section{Statistical methods}

Clinicopathological factors including age, obesity, histological grade of tumor, preoperative CEA, preoperative CA15-3, T stage, $\mathrm{N}$ stage, and menopausal status were assessed to determine whether they were associated with subtype change using chisquare or Fisher exact tests in univariate analysis. Factors that were significantly associated with subtype change in the univariate analysis were included in a multivariate analysis using logistic regression. All tests of significance were twosided, and a P-value of $<0.05$ was considered significant. Statistical analysis was carried out using IBM SPSS Statistics ver. 22.0 (IBM Co., Armonk, NY, USA).

\section{Ethical approval}

Approval was granted by the Institutional Review Board of Pusan National University (IRB No. 05-2018-166). Patient records and information were anonymized and identification was removed before analysis to protect personal information. All procedures performed in studies involving human participants were in accordance with the ethical standards of the institutional and/or national research committee and with the 1964 Helsinki declaration and its later amendments or
Table 1. Clinical and pathological characteristics of breast cancer patients evaluated by double-checking of core needle biopsy and surgical specimen $(n=620)$

\begin{tabular}{|c|c|}
\hline Characteristic & No. (\%) \\
\hline \multicolumn{2}{|l|}{ Age (yr) } \\
\hline$<50$ & $236(38.1)$ \\
\hline$\geq 50$ & $384(61.9)$ \\
\hline \multicolumn{2}{|l|}{ Body mass index $\left(\mathrm{kg} / \mathrm{m}^{2}\right)$} \\
\hline$<18.5$ (underweight) & $14(2.3)$ \\
\hline 18.5-22.9 (normal) & $220(35.5)$ \\
\hline 23-24.9 (overweight) & $157(25.3)$ \\
\hline$\geq 25$ (obese I) & $191(30.8)$ \\
\hline$\geq 30$ (obese II) & $38(6.1)$ \\
\hline \multicolumn{2}{|l|}{ Grade } \\
\hline 1 & $86(13.9)$ \\
\hline 2 & $302(48.7)$ \\
\hline 3 & $232(37.4)$ \\
\hline \multicolumn{2}{|l|}{ T stage } \\
\hline pT1 & $287(46.3)$ \\
\hline pT2 & $287(46.3)$ \\
\hline$\geq \mathrm{pT} 3$ & $46(7.4)$ \\
\hline \multicolumn{2}{|l|}{$\mathrm{N}$ stage } \\
\hline pNO & $392(63.2)$ \\
\hline $\mathrm{pN} 1$ & $161(26.0)$ \\
\hline $\mathrm{pN} 2$ & $41(6.6)$ \\
\hline $\mathrm{pN} 3$ & $26(4.2)$ \\
\hline \multicolumn{2}{|l|}{ Preoperative CEA } \\
\hline$<5$ & $572(92.3)$ \\
\hline$\geq 5$ & $48(7.2)$ \\
\hline \multicolumn{2}{|l|}{ Preoperative CA 15-3 } \\
\hline$<30$ & $609(98.2)$ \\
\hline$\geq 30$ & $11(1.8)$ \\
\hline \multicolumn{2}{|l|}{ Menopause status } \\
\hline Premenopausal & $290(46.8)$ \\
\hline Postmenopausal & $325(53.2)$ \\
\hline \multicolumn{2}{|l|}{ CNB subtype } \\
\hline HR+ / HER2+ & $416(67.1)$ \\
\hline HR+ / HER2- & $73(11.8)$ \\
\hline HR- / HER2+ & $54(8.7)$ \\
\hline HR- / HER2- & $77(12.4)$ \\
\hline \multicolumn{2}{|l|}{ SS subtype } \\
\hline $\mathrm{HR}+/ \mathrm{HER} 2+$ & $401(64.7)$ \\
\hline HR+ / HER2- & $73(11.8)$ \\
\hline HR- / HER2+ & $66(10.6)$ \\
\hline HR- / HER2- & $80(12.9)$ \\
\hline \multicolumn{2}{|l|}{ Histological type } \\
\hline IDC & $597(96.3)$ \\
\hline ILC & $23(3.7)$ \\
\hline
\end{tabular}

CNB, core needle biopsy; HR, hormone receptors (ER or PR); HER2, human epidermal growth factor receptor 2; IDC, invasive ductal carcinoma; ILC, invasive lobular carcinoma.

comparable ethical standards.

\section{RESULTS}

The clinicopathological characteristics of 620 breast cancer 
Table 2. Subtype change and additional treatments according to SS or CNB

\begin{tabular}{|c|c|c|c|c|c|}
\hline \multicolumn{3}{|c|}{ The change of subtypes } & \multirow{2}{*}{$\begin{array}{l}\text { Additional treatment plan } \\
\text { according to SS }\end{array}$} & \multirow{2}{*}{$\begin{array}{l}\text { Additional treatment plan } \\
\text { according to CNB }\end{array}$} & \multirow{2}{*}{ No. $(\%)$} \\
\hline CNB & $\rightarrow$ & SS & & & \\
\hline \multirow[t]{2}{*}{$\begin{array}{l}\text { HR+ } \\
\text { HER2+ }\end{array}$} & $\rightarrow$ & $\begin{array}{l}\text { HR+ } \\
\text { HER2- }\end{array}$ & - & Anti-HER2 & $2(4.4)$ \\
\hline & & $\begin{array}{l}\text { HR- } \\
\text { HER2+ }\end{array}$ & - & HTx. & $12(26.7)$ \\
\hline \multirow[t]{3}{*}{$\begin{array}{l}\text { HR+ } \\
\text { HER2- }\end{array}$} & $\rightarrow$ & $\begin{array}{l}\text { HR+ } \\
\text { HER2+ }\end{array}$ & Anti-HER2 & - & $10(22.2)$ \\
\hline & & $\begin{array}{l}\text { HR- } \\
\text { HER2+ }\end{array}$ & Anti-HER2 & HTx. & $1(2.2)$ \\
\hline & & $\begin{array}{l}\text { HR- } \\
\text { HER2- }\end{array}$ & - & HTx. & $9(20.0)$ \\
\hline \multirow[t]{2}{*}{$\begin{array}{l}\text { HR- } \\
\text { HER2+ }\end{array}$} & $\rightarrow$ & $\begin{array}{l}\text { HR+ } \\
\text { HER2+ }\end{array}$ & HTx. & - & $3(6.7)$ \\
\hline & & $\begin{array}{l}\text { HR- } \\
\text { HER2- }\end{array}$ & - & Anti-HER2 & $1(2.2)$ \\
\hline \multirow[t]{4}{*}{$\begin{array}{l}\text { HR- } \\
\text { HER2- }\end{array}$} & $\rightarrow$ & $\begin{array}{l}\mathrm{HR}+ \\
\mathrm{HER} 2+\end{array}$ & HTx. + Anti-HER2 & - & $1(2.2)$ \\
\hline & & $\begin{array}{l}\text { HR+ } \\
\text { HER2- }\end{array}$ & HTx. & - & $3(6.7)$ \\
\hline & & $\begin{array}{l}\text { HR- } \\
\text { HER2+ }\end{array}$ & Anti-HER2 & - & $3(6.7)$ \\
\hline & Total & & $21(46.7)$ & 25 (55.6) & $45(100)$ \\
\hline
\end{tabular}

SS, surgical specimen; CNB, core needle biopsy; HR, hormone receptors; HER2, human epidermal growth receptor-2; HTx., hormone therapy.

patients who were evaluated by a double-check of both CNB and SS are summarized in Table 1. The median age of these patients was 52 years (range, 23-93 years), and the median tumor size was $2.3 \mathrm{~cm}$ (range, $0.1-12.5 \mathrm{~cm}$ ). The proportions of patients who had HR+/HER2+, HR+/HER2-, HR-/HER2+, HR-/HER2- subtypes on CNB were $67.1 \%, 11.8 \%, 8.7 \%$, and $12.4 \%$, respectively, while the proportions of patients with HR+/HER2+, HR+/HER2-, HR-/ HER2+, HR-/HER2- subtypes on SS were $64.7 \%, 11.8 \%, 10.6 \%$, and $12.9 \%$, respectively.

The tumor subtyping of 45 patients (7.3\%) in this study differed between the preoperative $\mathrm{CNB}$ and the postoperative SS. There were 14 cases (31.1\%) that the subtypes changed from HR+/HER2+ to other types. There were 20 cases (44.4\%) that the subtypes changed HR+/HER2- to other types. 4 (8.9\%) were changed from HR-/HER2+ to others. Seven (15.6\%) were changed from HR-/HER2- to other types. The most common of these was the change from HR+/HER2+ to HR-/HER2+ (26.7\%). The change from HR+/HER2- to HR+/HER2+ (22.2\%), HR+/ HER2- to HR-/HER2- (20.0\%) was the next most common (Table 2).

The results of univariate analysis of factors associated with subtype change are presented in Table 3. Histological grade, CEA $\geq 5 \mathrm{ng} / \mathrm{mL}$, and T stage were significantly associated with subtype change. The likelihood of subtype change increased significantly with increasing histological grade $(\mathrm{P}<0.001$; odds ratio [OR], 3.693; 95\% confidence interval [CI], 1.941-7.025).
Patients with preoperative CEA $\geq 5 \mathrm{ng} / \mathrm{mL}$ were significantly more likely to have subtype change than patients with CEA < $5 \mathrm{ng} / \mathrm{mL}$ ( $\mathrm{P}=0.042 ; \mathrm{OR}, 2.399 ; 95 \% \mathrm{CI}, 1.009-5.707)$. The higher the T stage, the more likely the subtype was changed $(\mathrm{P}=0.015$; OR, 2.241; 95\% CI, 1.152-4.357).

However, age, BMI, CA15-3 level, N stage, and menopausal status were not significantly associated with subtype change.

In the multivariate analysis (Table 4), subtype changes were more common in high-grade breast cancer $(\mathrm{P}<0.001$; OR, 1.077; $95 \% \mathrm{CI}, 1.031-1.113)$. CEA $\geq 5 \mathrm{ng} / \mathrm{mL}$ was a significant predictor of subtype change ( $\mathrm{P}=0.032$; $\mathrm{OR}, 2.658$; 95\% CI, 1.088-6.490).

\section{DISCUSSION}

When adjuvant treatment was based on the results of the double-check, 21 (46.7\%), 25 (55.6\%) treatment were changed from CNB, SS only. 7 (16.6\%), 15 patients (33.3\%) had hormone or anti-HER2 treatment added from CNB only. 22 (48.9\%), 3 patients $(6.7 \%)$ additionally had hormone or anti-HER2 treatment from SS only.

Thus, additional treatments that would not have been used based on the results of SS alone were implemented based on the results of the $\mathrm{CNB}$, resulting in benefit for many patients. However, the double-check of both CNB and SS has the disadvantage of redundant costs. Therefore, it would be preferable to be able to select those patients who could benefit 
Table 3. Univariate analysis of factors associated with subtype change

\begin{tabular}{|c|c|c|c|c|}
\hline Variable & $\begin{array}{c}\text { Subtype changed } \\
(n=45) \\
\text { (\% of subgroup) }\end{array}$ & $\begin{array}{c}\text { Subtype unchanged } \\
(\mathrm{n}=575) \\
\text { (\% of subgroup) }\end{array}$ & OR $(95 \% \mathrm{Cl})$ & P-value \\
\hline Age $(y r)$ & & & & 0.967 \\
\hline$<50$ & $17(7.2)$ & 219 (92.8) & & \\
\hline$\geq 50$ & $28(7.3)$ & $356(92.7)$ & & \\
\hline Body mass index & & & & 0.578 \\
\hline Underweight $<18.5$ & $1(7.1)$ & $13(92.9)$ & & \\
\hline Normal 18.5-22.9 & $20(9.1)$ & $200(90.9)$ & & \\
\hline Overweight 23-24.9 & $9(5.7)$ & $148(94.3)$ & & \\
\hline Obese I 25 & $14(7.3)$ & $177(92.7)$ & & \\
\hline Obese II 30 & $1(2.6)$ & 37 (97.4) & & \\
\hline Tumor grade & & & & $<0.001$ \\
\hline 1 & $5(5.8)$ & $81(94.2)$ & & \\
\hline 2 & $10(3.3)$ & $292(96.7)$ & & \\
\hline 3 & $30(16.8)$ & $202(87.1)$ & & \\
\hline $\mathrm{G} 1+\mathrm{G} 2$ & $15(3.9)$ & $373(96.1)$ & $3.693(1.941-7.025)$ & $<0.001$ \\
\hline G3 & $30(12.9)$ & $202(87.1)$ & & \\
\hline Histology & & & & 0.584 \\
\hline IDC & $44(7.4)$ & $553(92.6)$ & & \\
\hline ILC & $1(4.3)$ & $22(95.7)$ & & \\
\hline Preoperative CEA & & & $2.399(1.009-5.707)$ & 0.042 \\
\hline$<5$ & $38(6.6)$ & $534(93.4)$ & & \\
\hline$\geq 5$ & 7 (14.6) & $41(85.4)$ & & \\
\hline Preoperative CA15-3 & & & & 0.813 \\
\hline$<30$ & $44(7.2)$ & $565(92.8)$ & & \\
\hline$\geq 30$ & $1(9.1)$ & $10(90.9)$ & & \\
\hline pT stage & & & & 0.049 \\
\hline pT1 & $13(4.5)$ & $274(95.5)$ & & \\
\hline pT2 & $27(9.4)$ & $260(45.2)$ & & \\
\hline pT3 & 5 (10.9) & 41 (89.1) & & \\
\hline $\mathrm{T} 1$ & $13(4.5)$ & $274(95.5)$ & $2.241(1.152-4.357)$ & 0.015 \\
\hline $\mathrm{T} 2+\mathrm{T} 3$ & $32(9.6)$ & 301 (90.4) & & \\
\hline pN stage & & & & 0.274 \\
\hline 0 & $27(6.9)$ & $365(93.1)$ & & \\
\hline 1 & $11(6.8)$ & $150(93.2)$ & & \\
\hline 2 & $6(14.6)$ & 35 (85.4) & & \\
\hline 3 & $1(3.8)$ & $25(96.2)$ & & \\
\hline Menopause & & & & 0.745 \\
\hline Premenopausal & $20(6.9)$ & $270(93.1)$ & & \\
\hline Postmenopausal & $25(7.6)$ & $305(92.4)$ & & \\
\hline
\end{tabular}

$\mathrm{OR}$, odds ratio; $\mathrm{Cl}$, confidence interval.

Table 4. Multivariate analysis of factors associated with subtype change

\begin{tabular}{lccc}
\hline \multicolumn{1}{c}{ Variable } & P-value & OR & $95 \% \mathrm{Cl}$ \\
\hline Grade $(\mathrm{G} 1 / \mathrm{G} 2$ vs. G3) & $<0.001$ & 1.077 & $1.031-1.113$ \\
Tumor size (pT1 vs. pT2/T3) & - & - & - \\
$\mathrm{CEA} \geq 5 \mathrm{ng} / \mathrm{mL}$ & 0.032 & 2.658 & $1.088-6.490$ \\
\hline
\end{tabular}

$\mathrm{OR}$, odds ratio; $\mathrm{Cl}$, confidence interval.

from the double-check.

Our study showed that clinicopathological factors, including the CEA level, tumor size, and histological grade, were associated with the likelihood of a change in molecular subtype of breast cancer between preoperative CNB and postoperative SS. Patients with CEA $\geq 5 \mathrm{ng} / \mathrm{mL}$ were significantly more likely to have a change in molecular subtype than those with CEA $<$ $5 \mathrm{ng} / \mathrm{mL}$ (14.6\% vs. $6.6 \%)$. Patients with high-grade tumor $(\geq 3)$ were more likely to change subtype than those with moderate and low-grade tumors (12.9\% vs. 3.9\%). Although multivariate analysis did not show a significant association, we also noted that the larger the size of the primary tumor, the more likely it was to change subtype ( $\mathrm{T} 1 \mathrm{vs}$. $\mathrm{T} 2+\mathrm{T} 3=4.5 \%$ vs. $9.6 \%$ ). 
CEA, which belongs to a family of cell surface glycoproteins, is the most widely used tumor marker in clinical practice. It is a marker for colorectal, gastrointestinal, lung, and breast cancer [27]. Elevated CEA in breast cancer is known to be associated with metastatic disease. Preoperative CEA measurements correlate with pathological tumor stage and circulating levels of CEA in breast cancer patients and are directly dependent on the size of both primary and metastatic tumors [28]. In our study, we found that high CEA, and high histological grade were associated with subtype changes between preoperative CNB and postoperative SS. Thus, it can be assumed that advanced breast cancer can further change the subtype.

This study had some limitations. First, because it was a singlecenter retrospective study, there might have been selective bias in the results, which are then difficult to generalize to other populations. Second, many patients underwent surgery at our hospital after being diagnosed with breast cancer at another hospital. When CNB was performed at another hospital, we did not repeat it. However, slides obtained from other hospitals were reexamined by our pathologists, who reported the biopsy results. Slides from other hospitals might have had technical problems with sample collection and fixation that we could not control. Third, we exclude unusual histological groups such as ductal carcinoma in situ, lobular carcinoma in situ, mucinous, metaplastic, papillary, etc. So, we do not know about the association of CEA with the unusual groups. To study the effect of CEA on unusual group, it is necessary to collect more data from the unusual histological groups.

In conclusion, double-checking of CNB and SS samples for evaluation of molecular subtype is necessary to plan adjuvant therapy in breast cancer. Depending on the results of the double-check, the patients may benefit from additional treatment. However, because of its cost-inefficiency, this double-check cannot be performed for all patients. It would be desirable to be able to select those patients who would benefit more from double-checking of their tumor molecular subtype.

The results of the present study indicate that patients with moderate- to high-grade tumors or CEA $\geq 5 \mathrm{ng} / \mathrm{mL}$ are most likely to undergo subtype changes and to require examination of the molecular subtype of their tumor by preoperative CNB.

Patients with preoperative $\mathrm{CEA} \geq 5 \mathrm{ng} / \mathrm{mL}$ are required a double-check to determine the molecular subtype of breast cancer. When high-grade breast cancer is found on postoperative histologic examination, the results of IHC should be reevaluated through tissue obtained from a preoperative CNB.

\section{CONFLICTS OF INTEREST}

No potential conflict of interest relevant to this article was reported.

\section{ACKNOWLEDGEMENTS}

This study was supported by Research Institute for Convergence of Biomedical Science and Technology, Pusan National University Yangsan Hospital Compliance with ethical standards.

\section{REFERENCES}

1. Arnedos M, Nerurkar A, Osin P, A'Hern R, Smith IE, Dowsett M. Discordance between core needle biopsy ( $\mathrm{CNB}$ ) and excisional biopsy (EB) for estrogen receptor (ER), progesterone receptor (PgR) and HER2 status in early breast cancer (EBC). Ann Oncol 2009;20:1948-52.

2. Lorgis V, Algros MP, Villanueva C, Chaigneau L, Thierry-Vuillemin A, Nguyen $\mathrm{T}$, et al. Discordance in early breast cancer for tumour grade, estrogen receptor, progesteron receptors and human epidermal receptor-2 status between core needle biopsy and surgical excisional primary tumour. Breast 2011;20:284-7.

3. Burge CN, Chang HR, Apple SK. Do the histologic features and results of breast cancer biomarker studies differ between core biopsy and surgical excision specimens? Breast 2006;15:167-72.

4. Goldhirsch A, Wood WC, Coates AS, Gelber RD, Thurlimann B, Senn HJ, et al. Strategies for subtypes--dealing with the diversity of breast cancer: highlights of the St. Gallen International Expert Consensus on the Primary Therapy of Early Breast Cancer 2011. Ann Oncol 2011;22: 1736-47.

5. Polyak K. Heterogeneity in breast cancer. J Clin Invest 2011;121:3786-8.

6. National Comprehensive Cancer Network. NCCN Guidelines: breast cancer [Internet].
Fort Wathington (PA): National Comprehensive Cancer Network; 2016 [cited 2019 Jan 18]. Available from: https://www. nccn.org/professionals/physician_gls/pdf/ breast.pdf.

7. Early Breast Cancer Trialists' Collaborative Group (EBCTCG), Peto $R$, Davies C, Godwin J, Gray R, Pan HC, et al. Comparisons between different polychemotherapy regimens for early breast cancer: meta-analyses of long-term outcome among 100,000 women in 123 randomised trials. Lancet 2012;379:432-44.

8. Early Breast Cancer Trialists' Collaborative Group (EBCTCG), Davies C, Godwin J, Gray R, Clarke M, Cutter D, et al. Relevance 
of breast cancer hormone receptors and other factors to the efficacy of adjuvant tamoxifen: patient-level meta-analysis of randomised trials. Lancet 2011;378:77184.

9. Slamon D, Eiermann W, Robert N, Pienkowski T, Martin M, Press M, et al. Adjuvant trastuzumab in HER2-positive breast cancer. N Engl J Med 2011;365:1273-83.

10. You K, Park S, Ryu JM, Kim I, Lee SK, Yu J, et al. Comparison of core needle biopsy and surgical specimens in determining intrinsic biological subtypes of breast cancer with immunohistochemistry. J Breast Cancer 2017;20:297-303.

11. Bruening W, Fontanarosa J, Tipton K, Treadwell JR, Launders J, Schoelles K. Systematic review: comparative effectiveness of core-needle and open surgical biopsy to diagnose breast lesions. Ann Intern Med 2010;152:238-46.

12. Pettine S, Place R, Babu S, Williard W, Kim D, Carter P. Stereotactic breast biopsy is accurate, minimally invasive, and cost effective. Am J Surg 1996;171:474-6.

13. Senkus E, Kyriakides S, Ohno S, PenaultLlorca F, Poortmans P, Rutgers E, et al. Primary breast cancer: ESMO Clinical Practice Guidelines for diagnosis, treatment and follow-up. Ann Oncol 2015;26 Suppl 5:v8-30.

14. Chen X, Sun L, Mao Y, Zhu S, Wu J, Huang $\mathrm{O}$, et al. Preoperative core needle biopsy is accurate in determining molecular subtypes in invasive breast cancer. BMC Cancer 2013;13:390.

15. Arens N, Bleyl U, Hildenbrand R. HER2/ neu, p53, Ki67, and hormone receptors do not change during neoadjuvant chemotherapy in breast cancer. Virchows Arch 2005:446:489-96.

16. Chen X, Yuan Y, Gu Z, Shen K. Accuracy of estrogen receptor, progesterone receptor, and HER2 status between core needle and open excision biopsy in breast cancer: a meta-analysis. Breast Cancer Res Treat 2012;134:957-67.

17. Berghuis AMS, van Deurzen CHM, Koffijberg H, Terstappen LWMM, Sleijfer S, IJzerman MJ. Real-world data on discordance between estrogen, progesterone, and HER2 receptor expression on diagnostic tumor biopsy versus tumor resection material. Breast Cancer Res Treat 2019;175:451-8.

18. Allred DC, Harvey JM, Berardo M, Clark GM. Prognostic and predictive factors in breast cancer by immunohistochemical analysis. Mod Pathol 1998;11:155-68.

19. Wolff AC, Hammond ME, Hicks DG, Dowsett M, McShane LM, Allison KH, et al. Recommendations for human epidermal growth factor receptor 2 testing in breast cancer: American Society of Clinical Oncology/College of American Pathologists clinical practice guideline update. J Clin Oncol 2013:31:3997-4013.

20. Carey LA, Dees EC, Sawyer L, Gatti L, Moore DT, Collichio F, et al. The triple negative paradox: primary tumor chemosensitivity of breast cancer subtypes. Clin Cancer Res 2007:13:2329-34.

21. Cheang MC, Chia SK, Voduc D, Gao D, Leung S, Snider J, et al. Ki67 index, HER2 status, and prognosis of patients with luminal B breast cancer. J Natl Cancer Inst 2009;101:736-50.

22. Cheang MC, Voduc D, Bajdik C, Leung S, McKinney S, Chia SK, et al. Basal-like breast cancer defined by five biomarkers has superior prognostic value than triplenegative phenotype. Clin Cancer Res 2008;14:1368-76.

23. World Health Organaization; Internatio- nal Obesity TaskForce. The Asia-Pacific perspective: redefining obesity and its treatment. Sydney: Health Communications Australia; 2000.

24. Duffy MJ. Serum tumor markers in breast cancer: are they of clinical value? Clin Chem 2006;52:345-51.

25. Molina R, Auge JM, Farrus B, Zanon G, Pahisa J, Munoz M, et al. Prospective evaluation of carcinoembryonic antigen (CEA) and carbohydrate antigen 15.3 (CA 15.3) in patients with primary locoregional breast cancer. Clin Chem 2010;56:1148-57.

26. Li X, Dai D, Chen B, Tang H, Xie X, Wei W. Clinicopathological and prognostic significance of cancer antigen 15-3 and carcinoembryonic antigen in breast cancer: a meta-analysis including 12,993 patients. Dis Markers 2018;2018:9863092.

27. Shao Y, Sun X, He Y, Liu C, Liu H. Elevated levels of serum tumor markers CEA and CA15-3 are prognostic parameters for different molecular subtypes of breast cancer. PLoS One 2015;10:e0133830.

28. Park BW, Oh JW, Kim JH, Park SH, Kim KS, Kim JH, et al. Preoperative CA 15-3 and CEA serum levels as predictor for breast cancer outcomes. Ann Oncol 2008; 19:675-81.

29. Stieber P, Nagel D, Blankenburg I, Heinemann V, Untch M, Bauerfeind I, et al. Diagnostic efficacy of CA 15-3 and CEA in the early detection of metastatic breast cancer-A retrospective analysis of kinetics on 743 breast cancer patients. Clin Chim Acta 2015:448:228-31.

30. Gunczler P, Ogris E, Maca S, Danmayr E. Tumor markers in breast cancer: on the diagnostic value of serum determinations in clinical freedom from tumor and manifest disease. Onkologie 1989;12:209-14. 